\title{
NOTE
}

\section{ATRP-RCM Synthesis of 8-Shaped Poly(methyl acrylate) Using a 4-Armed Star Telechelics}

\author{
By Shotaro HAYASHI, Kaoru ADACHI, and Yasuyuki TEZUKA*
}

KEY WORDS: 8-Shaped Polymer / Atom Transfer Radical Polymerization / Keck Allylation / Ring-closing Metathesis /

Cyclic and multicyclic polymers have drawn increasing attention due to their unique architectures, i.e., free of chain ends. ${ }^{1}$ A number of protocols including, in particular, the ringexpansion polymerization ${ }^{2}$ and the end-to-end polymer cyclization, ${ }^{3}$ have now been developed for the selective and effective synthesis of single cyclic polymers to realize novel properties and functions unattainable by conventional linear or branched counterparts.

We have also proposed a metathesis polymer cyclization (MPC) process, i.e., a ring-closing metathesis (RCM) reaction with a linear telechelic precursor having olefinic end groups under dilution. ${ }^{4}$ And the effective and selective synthesis of cyclic polyacrylate has been achieved through atom transfer radical polymerization (ATRP)-Keck allylation and the subsequent RCM reaction. ${ }^{5}$ In this process, the key telechelic prepolymer was produced by the ATRP using a difunctional initiator and the terminal bromide group was quantitatively converted to allyl group by the reaction with allyltributyltin. The subsequent intramolecular RCM reaction proceeded even under dilution in the presence of Grubbs catalyst to give a cyclic polymer in high efficiency.

On the other hand, such a dicyclic as 8-shaped polymer ${ }^{6}$ has yet been an ongoing challenge in the synthetic polymer chemistry. ${ }^{7}$ We have shown that 8-shaped polymers are obtainable through an electrostatic self-assembly formed by two units of telechelic precursor having moderately strained cyclic ammonium salt end groups carrying one unit of tetracarboxylate counter anion. ${ }^{3 a, 8}$ Alternatively, inter- and intramolecular metathesis condensation process have been applied ${ }^{9}$ between two units of a cyclic prepolymer having an allyloxy group (Scheme 1-a), and with a twin-tailed tadpole polymer precursor (Scheme 1-b), as well as with a cyclic polymer precursor having two allyloxy groups at the opposite positions (Scheme 1-c), respectively. The intramolecular metathesis condensation has also been applied with an $\mathrm{H}$-shaped precursor having allyloxy end groups at each chain ends, to produce other types of dicyclic polymers having $\theta$ and manacle topologies (Scheme 1-d). ${ }^{10}$

As an extension of the preceding studies, we report in this paper on the synthesis of an 8-shaped polymer through the double ring-closing metathesis reaction using a 4-armed star polymer precursor, synthesized by means of the ATRP of methyl acrylate using a tetrafunctional initiator (Scheme 2). Since the ATRP has been recognized as a versatile means to give living star polymers upto hexafunctionalities by using multi-functional initiators, ${ }^{11}$ complex multicyclic polymers will be obtainable through the MPC process with end-functional star polymers.

\section{EXPERIMENTAL}

\section{Materials}

A tetrafunctional ATRP initiator, pentaerythritol tetrakis(2-bromoisobutyrate), 1, was synthesized by the procedure reported previously. ${ }^{11 \mathrm{~b}}$ Methyl acrylate (99.0\%, Aldrich) was distilled under reduced pressure. Cuprous bromide $(\mathrm{CuBr}$, Nacalai tesuque), allyltri- $n$-butyltin (99.0\%, Aldrich), Grubbs catalyst first generation (Aldrich) was used as received. Methylene chloride (99.0\%, Kanto Chemical Co) was distilled over $\mathrm{CaH}_{2}$. Triethylamine (99.5\%, Kanto Chemical Co) was distilled. THF (99.5\%, Kanto Chemical Co) was distilled over $\mathrm{Na}$ wire. Alumina (Wako Chemical Co., Aluminium Oxide, activated, about $45 \mu \mathrm{m}, \mathrm{ca} .300 \mathrm{mesh}$ ) and other chemicals are used as received.

Synthesis of 4-Armed Star PMA having Allyl End Groups, 2. Methyl acrylate $(560 \mathrm{mg}, 5.6 \mathrm{mmol}), 2,2^{\prime}$-bipyridine (bpy) (61 mg, $0.39 \mathrm{mmol}), \mathrm{CuBr}(21 \mathrm{mg}, 0.15 \mathrm{mmol})$, tetrafunctional initiator, 1, $(66 \mathrm{mg}, 0.090 \mathrm{mmol})$ were placed in a $10 \mathrm{~mL}$ reaction tube, and the mixture was subjected to three freezepump-thaw cycles. The mixture was then heated to $90^{\circ} \mathrm{C}$ for $20 \mathrm{~min}$, and benzene $(0.5 \mathrm{~mL})$ and allyltri- $n$-butyltin $(320 \mathrm{mg}$, $0.96 \mathrm{mmol}$ ) were added. The reaction was allowed to continue at $90^{\circ} \mathrm{C}$ under stirring for $8 \mathrm{~h}$. The polymer product was recovered after the treatment with alumina, and finally purified by the precipitation twice into hexane. Yield $=362 \mathrm{mg}$. ${ }^{1} \mathrm{H} \mathrm{NMR}$ of $2\left(\mathrm{CDCl}_{3}\right): \delta 1.22-2.15\left(\mathrm{br}, \mathrm{CH}_{2} \mathrm{CHCOOCH}_{3}\right)$, 2.15-2.55 (br, $\mathrm{CH}_{2} \mathrm{CHCOOCH}_{3}$ ), 3.47-3.84 (br, $\mathrm{CH}_{2} \mathrm{CHCOO}-$ $\left.\mathrm{CH}_{3}\right), 4.10\left(\mathrm{~s}, \mathrm{CCH}_{2} \mathrm{O}(\mathrm{CO})\right), 5.04\left(\mathrm{~m}, \mathrm{CH}_{2} \mathrm{CH}=\mathrm{CH}_{2}\right), 5.67(\mathrm{~m}$, $\mathrm{CH}_{2} \mathrm{CH}=\mathrm{CH}_{2}$ ).

Synthesis of 8-Shaped PMA, 3. The 4-armed star PMA, 2, 
<smiles>C1CCCCCCC1</smiles><smiles>C1CCCCCC1</smiles><smiles>CC(C)C</smiles><smiles>CC1CCCCCCCCCCCCC1</smiles><smiles>OCC1(CO)CCCCC1</smiles><smiles>CCCC1CCC2CCCCCC2CC1</smiles>
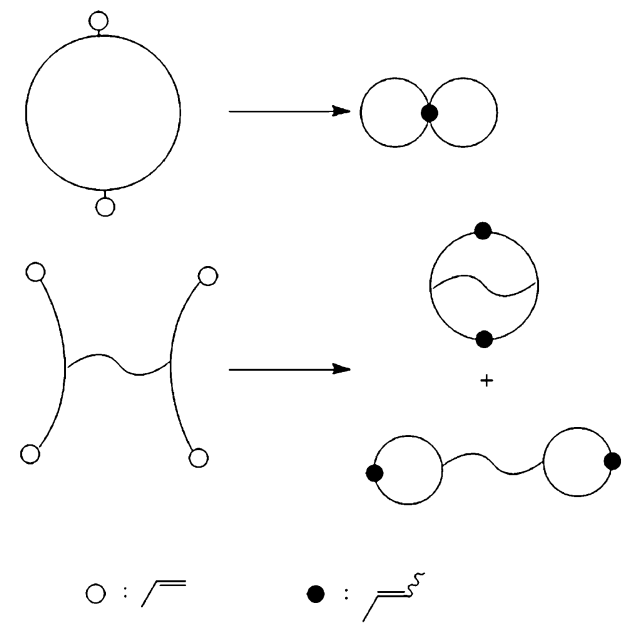

Scheme 1. Synthesis of dicyclic polymers by RCM process.

$(80 \mathrm{mg})$ and methylene chloride $(200 \mathrm{~mL})$ were placed in a $300 \mathrm{~mL}$ flask. Thereupon Grubbs catalyst 1st generation (40 $\mathrm{mg}, 48 \times 10^{-3} \mathrm{mmol}$ ) was added. The reaction was conducted under reflux for $48 \mathrm{~h}$, and the solvent was evaporated. The polymer product was recovered after the treatment with the alumina column and finally isolated by the precipitation into hexane. Yield $=38 \mathrm{mg}(48 \%)$. ${ }^{1} \mathrm{H} \mathrm{NMR}$ of $3\left(\mathrm{CDCl}_{3}\right): \delta 1.22-$ 2.15 (br, $\mathrm{CH}_{2} \mathrm{CHCOOCH}_{3}$ ), 2.15-2.55 (br, $\mathrm{CH}_{2} \mathrm{CHCOOCH}_{3}$ ), 3.47-3.84 (br, $\mathrm{CH}_{2} \mathrm{CHCOOCH}_{3}$ ), 4.10 (s, $\mathrm{CCH}_{2} \mathrm{O}(\mathrm{CO})$ ), 5.34 (m, $\mathrm{CH}_{2} \mathrm{CH}=\mathrm{CH}$, cis and trans).

\section{Measurements}

${ }^{1} \mathrm{H}$ NMR spectra were recorded with a JEOL JNM AL300 apparatus in $\mathrm{CDCl}_{3}$ at ambient temperature. The proton chemical shifts (ppm) were referenced from the signal of tetramethylsilane. MALDI-TOF MS spectra were taken on a SHIMADZU AXIMA-CFR mass spectrometer. The spectrometer was equipped with a nitrogen laser $(\lambda=337 \mathrm{~nm})$ and with pulsed ion extraction. The operation was performed at an accelerating potential of $20 \mathrm{kV}$ by a linear-positive ion mode. The sample polymer solution $(10 \mathrm{~g} / \mathrm{L})$ was prepared in THF. The matrix, 1,8-dihydroxy-9 $(10 \mathrm{H})$ anthracenone (dithranol, Aldrich) was dissolved in THF $(30 \mathrm{~g} / \mathrm{L})$ and sodium trifluoroacetate was dissolved in THF $(10 \mathrm{~g} / \mathrm{L})$. The polymer solution $(90 \mu \mathrm{L})$ was then mixed with $30 \mu \mathrm{L}$ of matrix solution. A $1 \mu \mathrm{L}$ portion of the final solution was deposited onto a sample target plate and allowed to dry in air at room temperature. Mass values were calibrated by the three-point method with insulin $\beta$ (Sigma-Aldrich) at 3497.0 (plus $\mathrm{H}^{+}$), bovine insulin (Aldrich) at 5733.5 (plus $\mathrm{H}^{+}$), and myoglobin (Aldrich) at 16950.9 (plus $\mathrm{H}^{+}$). SEC measurements were performed using a Shodex GPC101 equipped with a refractive index detector model Shodex RI-71S. A column of shodex LF-804 was employed with THF as an eluent at a flow rate of $1.0 \mathrm{~mL} / \mathrm{min}$. In a typical procedure, $30 \mu \mathrm{L}$ of sample solution (sample concentration of $1 \mathrm{wt} \%$ ) was injected.

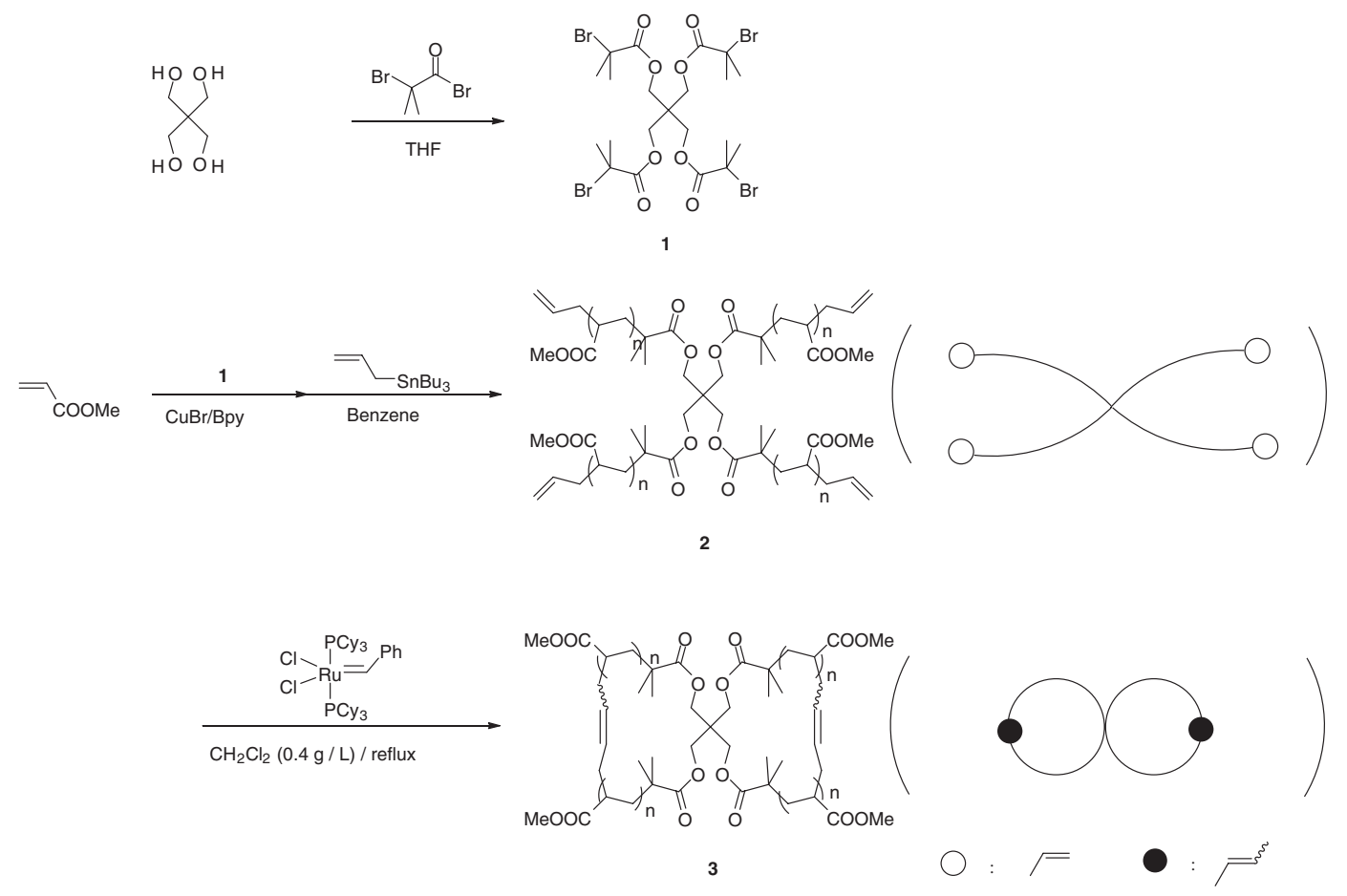

Scheme 2. Synthesis of 8-shaped PMA through ATRP-RCM process. 

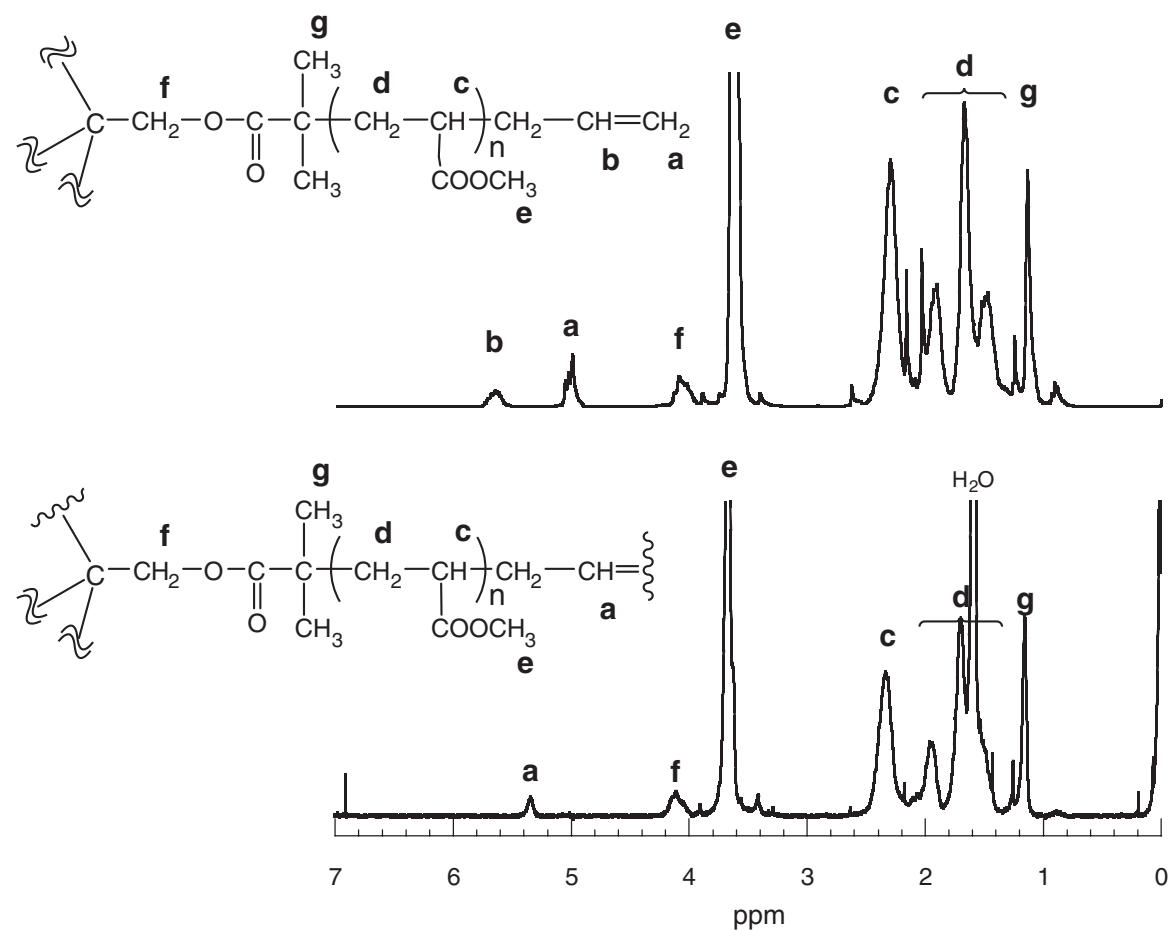

Figure 1. $300 \mathrm{MHz}{ }^{1} \mathrm{H}$ NMR spectra of the 4-armed star PMA precursor (2, top) and the 8-shaped PMA obtained by the metathesis condensation (3, bottom). (The signal for allyl methylene protons of $\mathbf{2}$ and of $\mathbf{3}$ are not visible by overlapping with the main-chain protons, $\mathbf{d})\left(\mathrm{CDCl}_{3}\right)$.

\section{RESULTS AND DISCUSSION}

A 4-armed star poly(methyl acrylate), PMA, having allyl end groups has been prepared by the ATRP of methyl acrylate using pentaerythritol tetrakis(2-bromoisobutyrate), $\mathbf{1}$, as a tetrafunctional initiator, ([MA]:[1] :[Cu(I)Br]:[bpy] = 36:1.0: $0.81: 2.2,90 \mu \mathrm{L}, 20 \mathrm{~min}$ ), and the subsequent in situ allylation of the end groups with allyltributyltin. ${ }^{8 d}$ The ${ }^{1} \mathrm{H}$ NMR spectrum of the product (Figure 1, top), showed signals due to the methylene protons in the core unit $(4.10 \mathrm{ppm})$ and those due to allyl groups located at the chain ends (5.04 and $5.67 \mathrm{ppm})$. Methyne proton signals adjacent to the terminal bromide atom $(4.23 \mathrm{ppm})$ was eliminated after the allylation reaction. ${ }^{8 \mathrm{~d}}$ The MALDI-TOF mass spectra (Figure 2, top) showed a uniform series of peaks corresponding to PMA (peak interval of 86 mass units). Each peak corresponds exactly to the molar mass summing up the 4-armed star structure having allyl groups at each chain ends. As an example, the peak (assumed to be the adduct with $\mathrm{Na}^{+}$) at 4042.9 corresponds to the product with the number of monomer methyl acrylate units, $\mathrm{N}_{\mathrm{MA}}$ of 40 , $\left(\mathrm{C}_{4} \mathrm{H}_{6} \mathrm{O}_{2}\right) \times 40+\mathrm{C}_{33} \mathrm{H}_{52} \mathrm{O}_{8}$, plus $\mathrm{Na}^{+}$as 4043.39 .

The double metathesis condensation reaction of the star polymer precursor, 2, was then performed in methylene chloride at the dilution of $0.4 \mathrm{~g} / \mathrm{L}$ in the presence of a Grubbs catalyst 1 st generation under reflux for $48 \mathrm{~h}$ to ensure the total consumption of allyl end groups. The 8-shaped polymer product, 3, was isolated in $48 \%$ yield after the purification through alumina column followed by precipitation into hexane. The ${ }^{1} \mathrm{H}$ NMR (Figure 1, bottom) showed that the signals due to the allyl groups in $\mathbf{2}$ at 5.67 and $5.04 \mathrm{ppm}$ are totally removed after the reaction, and that those due to the inner olefinic unit (cis and trans signals both at $5.33 \mathrm{ppm}$ ) appeared instead. The MALDI-TOF mass spectrum of the product after the reaction (Figure 2, bottom) showed that all peaks correspond exactly to the molar mass for the expected structure produced by the double metathesis condensation of four allyl groups in the 4armed star polymer precursor, 2 . Thus, the peak (assumed to be the adduct with $\mathrm{Na}^{+}$) at 3986.6 corresponds to the product with the number of monomer MA units, $\mathrm{N}_{\mathrm{MA}}$ of $40,\left(\mathrm{C}_{4} \mathrm{H}_{6} \mathrm{O}_{2}\right) \times$ $40+\mathrm{C}_{29} \mathrm{H}_{44} \mathrm{O}_{8}$, plus $\mathrm{Na}^{+}$as 3987.28. Since the 8-shaped PMA product, 3 , is produced from the 4-armed PMA precursor, 2, by the elimination of two ethylene molecule, their molecular weights differ by $56,(28 \times 2)$, mass units. And this was indeed confirmed by comparing the two spectra in Figure 2. It is also remarkable that neither peak were detectable corresponding to twin-tail tadpole PMA formed by single metathesis condensation of 4-armed star PMA precursor, nor corresponding to unreacted 4-armed star PMA. Also due to the detection limit of the molar mass (around $10^{4}$ ) by the current MALDI condition, no peaks were visible for dimeric byproducts obtainable by intermolecular metathesis condensation. Thus it is confirmed that the 8-shaped PMA was obtained selectively.

SEC traces of the 4-armed star PMA precursor and the 8shaped PMA were compared in Figure 3. Both traces retained unimodal distribution to indicate negligible chain degradation during the metathesis process. It has been shown theoretical$1 \mathrm{y}^{12 \mathrm{a}, 12 \mathrm{~b}, 12 \mathrm{c}}$ as well as from SEC measurements ${ }^{8,12 \mathrm{~d}, 12 \mathrm{e}}$ that 4armed star polymers have smaller hydrodynamic volume than 


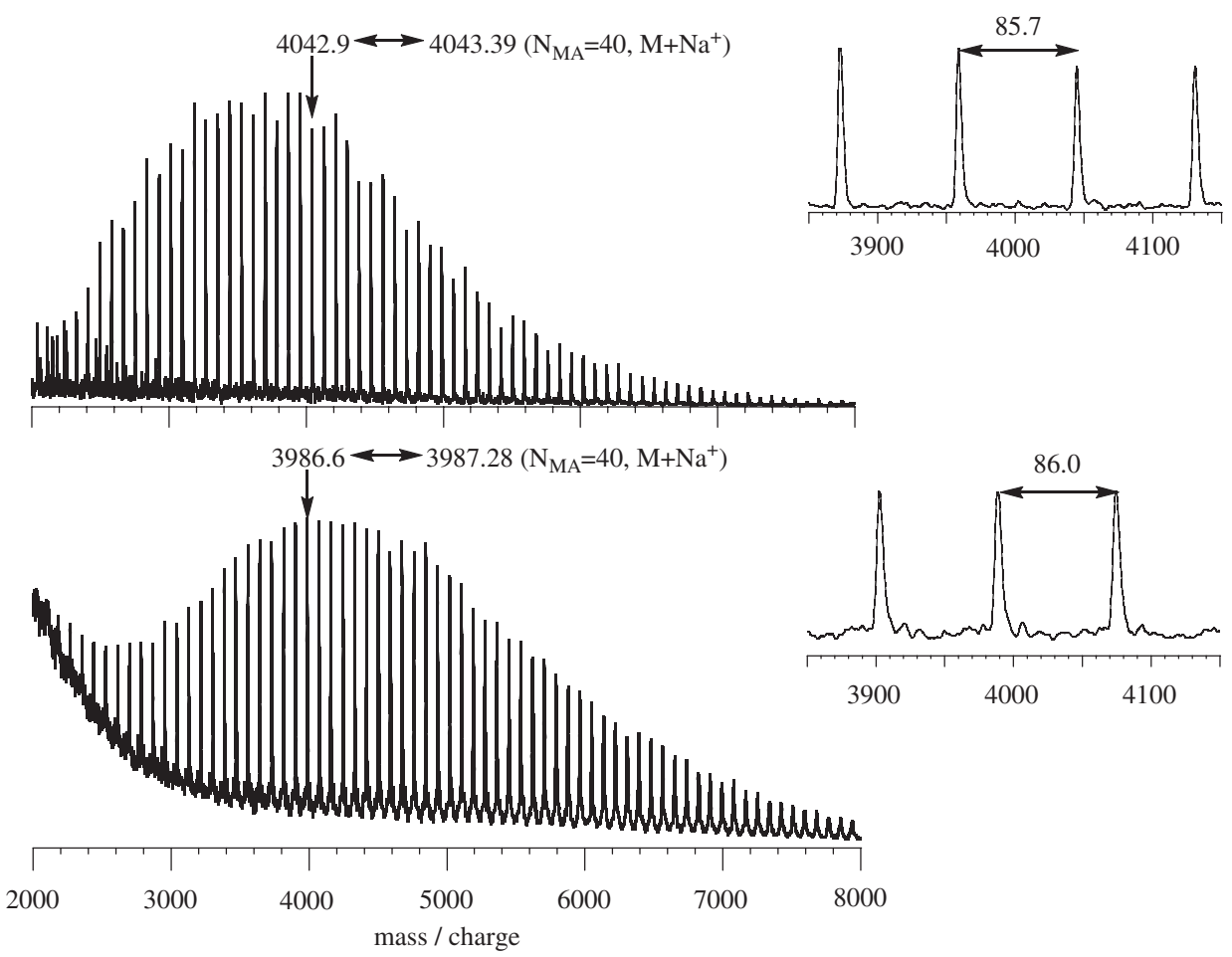

Figure 2. MALDI-TOF MS spectra of the 4-armed star PMA precursor (2, top) and the 8-shaped PMA obtained by the metathesis condensation (3, bottom). (linear mode, matrix: dithranol with sodium trifluoroacetate).

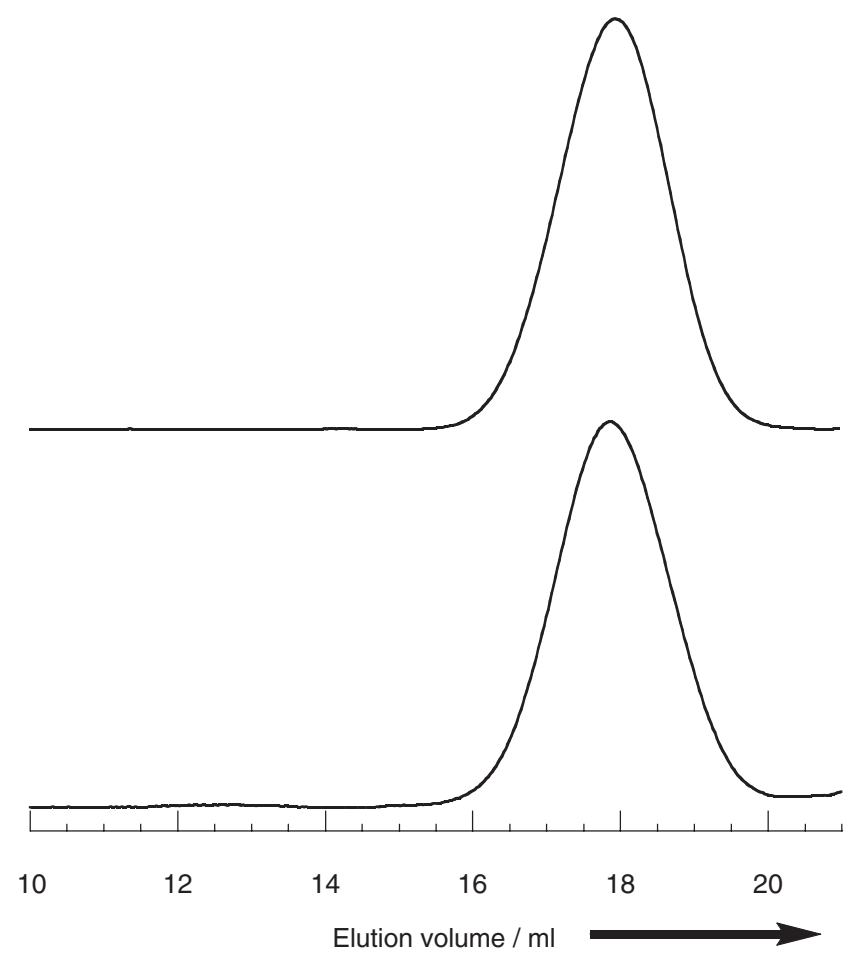

Figure 3. SEC traces (RI) the 4-armed star PMA precursor (2, top) and the 8-shaped PMA obtained by the metathesis condensation (3, bottom). (Shodex LF-804, eluent: THF, $1.0 \mathrm{~mL} / \mathrm{min}$ ). its linear counterpart, and 8-shaped polymers are smaller in their 3D sizes than either linear or simple ring counterparts. Moreover, the 8-shaped polymer could be smaller in its hydrodynamic volume than the 4-armed star precursor, since the former is produced by the double cyclization of the latter. However, the apparent peak molecular weight, $M_{\mathrm{p}}$, as the measure of the 3D size, of the isolated 8-shaped PMA $\left(M_{\mathrm{p}}=8900\right.$, PDI $=1.36$, polystyrene standard $)$ was almost unchanged from that of 4-armed star PMA $\left(M_{\mathrm{p}}=8300\right.$, PDI $=1.35$, polystyrene standard). This could be due to the loss of a part of the 8-shaped polymer product during the purification procedure ( $48 \%$ recovery yield), and the observed number-average molecular weights (estimated by NMR analysis) were not constant but reduced for the 8-shaped polymer (4600) from the 4-armed star precursor (5600). Thus in the present stage, we have reserved to undertake the rigorous examination of the $3 \mathrm{D}$ size of the 8 -shaped polymer in comparison with the 4 -armed star polymer.

\section{CONCLUSION}

An 8-shaped polymer was synthesized through double RCM reaction of a 4-armed star PMA precursor having four allyl end groups, obtained through the ATRP of methyl acrylate with tetrafunctional initiator and subsequent end-capping radical reaction (Keck allylation) with allyltributyltin. This study shows that the combination of ATRP and RCM technique provides a versatile means to produce new polymer material of unconventional topologies. 
Acknowledgment. We are grateful to Professor M. Kakimoto for our access to the NMR and GPC apparatus. This work was supported partly by a grant from the Ministry of Education, Culture, Sports, Science, and Technology, Japan (17350054).

Received: February 5, 2008

Accepted: March 11, 2008

Published: April 23, 2008

\section{REFERENCES}

1. a) "Cyclic polymers," 2nd ed, J. A. Semlyen, Ed., Kluwer Academic Publishers, Dordrecht, The Netherlands, 2000.

b) J. Roovers and P. M. Toporowski, Macromolecules, 16, 843 (1983).

c) G. Hild, C. Strazielle, and P. Rempp, Eur. Polym. J., 19, 721 (1983).

d) R. Chen, G. G. Nossarev, and T. E. Hogen-esch, J. Polym. Sci., Part A: Polym. Chem., 42, 5488 (2004).

e) K. A. Alberty, T. E. Hogen-Esch, and S. Carlotti, Macromol. Chem. Phys., 206, 1035 (2005)

f) N. Chen, N. Maeda, M. Tirrell, and J. Israelachvili, Macromolecules, 38, 3491 (2005).

g) K. Hur, R. G. Winker, and D. Y. Yoon, Macromolecules, 39, 3975 (2006).

2. a) C. W. Bielawski, D. Benitez, and R. H. Grubbs, J. Am. Chem. Soc., 125, 8424 (2003).

b) P. Hodge and S. D. Kawau, Angew. Chem., Int. Ed., 42, 2412 (2003).

c) H. Kudo, S. Makino, A. Kameyama, and T. Nishikubo, Macromolecules, 38, 5964 (2005).

d) D. A. Culkin, W. Jeong, S. Csihony, E. D. Gomez, N. P. Balsara, J. L. Hedrick, and R. M. Waymouth, Angew. Chem., Int. Ed., 46, 2627 (2007).

3. a) H. Oike, H. Imaizumi, T. Mouri, Y. Yoshioka, A. Uchibori, and Y. Tezuka, J. Am. Chem. Soc., 122, 9592 (2000).

b) M. Kubo, T. Nishigawa, T. Uno, T. Itoh, and H. Sato, Macromolecules, 36, 9264 (2003).

c) B. A. Laurent and S. M. Grayson, J. Am. Chem. Soc., 128, 4238 (2006).

d) H. Li, A. Debuigne, R. Jerome, and P. Lecomte, Angew. Chem.,
Int. Ed., 45, 2264 (2006).

4. Y. Tezuka and R. Komiya, Macromolecules, 35, 8667 (2002).

5. S. Hayashi, K. Adachi, and Y. Tezuka, Chem. Lett., 36, 982 (2007).

6. a) M. Kubo, T. Hayashi, H. Kobayashi, and T. Itoh, Macromolecules, 31, 1053 (1998).

b) A. E. Madani, J.-C. Favier, P. Hemery, and P. Sigwalt, Polym. Int., 27, 353 (1992)

c) M. Antonietti and K. J. Folsch, Makromol. Chem. Rapid Commun., 9, 423 (1988).

d) M. Schappacher and A. Deffieux, Macromolecules, 28, 2629 (1995).

7. a) Y. Tezuka and H. Oike, Prog. Polym. Sci., 27, 1069 (2002).

b) Y. Tezuka, R. Komiya, Y. Ido, and K. Adachi, React. Funct. Polym., 67, 1233 (2007).

c) Y. Tezuka, N. Takahashi, T. Satoh, and K. Adachi, Macromolecules, 40, 7910 (2007).

8. H. Oike, M. Hamada, S. Eguchi, Y. Danda, and Y. Tezuka, Macromolecules, 34, 2776 (2001).

9. Y. Tezuka, R. Komiya, and M. Washizuka, Macromolecules, 36, 12 (2003).

10. Y. Tezuka and F. Ohashi, Macromol. Rapid Commun., 26, 608 (2005).

11. a) K. Matyjaszewski and J. Xia, Chem. Rev., 101, 2921 (2001).

b) K. Matyjaszewski, P. J. Miller, J. Pyun, G. Kickelbick, and S. Diamanti, Macromolecules, 32, 6526 (1999).

c) V. Coessens and K. Matyjazewski, Macromol. Rapid Commun., 20, 66 (1999).

d) V. Coessens and K. Matyjazewski, Macromol. Rapid Commun., 20, 127 (1999).

e) V. Coessens, J. Pyun, J. Miller, S. G. Gaynor, and K. Matyjaszewski, Macromol. Rapid Commun., 21, 103 (2000).

f) N. V. Tsarevsky, B. S. Sumerlin, and K. Matyjazewski, Macromolecules, 38, 3558 (2005).

g) D. Xie, Long-Gu. Park, and J. Zhao, Dent. Mater., 23, 395 (2007).

12. a) B. H. Zimm and W. H. Stockmayer, J. Chem. Phys., 17, 1301 (1949).

b) C. R. A. Abreu and F. A. Escobedo, Macromolecules, 38, 8532 (2005).

c) A. A. Gorbunov and A. V. Vakhrushev, Polymer, 45, 6761 (2004). d) H. Oike, T. Yaguchi, and Y. Tezuka, Macromol. Chem. Phys., 200, 768 (1999).

e) Y. Tezuka and K. Fujiyama, J. Am. Chem. Soc., 127, 6266 (2005). 